\title{
Becoming Really Dead: Dying by Degrees
}

\section{INTRODUCTION}

In the field of criminal history Vic Gatrell alerted a generation of historians to the agency of the English crowd and visceral nature of the execution act. ${ }^{1}$ It was a brutalising, demeaning, painful, spectacle of retributive justice throughout the long eighteenth-century. Peter Linebaugh correspondingly highlighted how mob hostility to the surgeons broke out at bungled executions during the 1730s in London. ${ }^{2}$ Frequently the hangman was bribed to mishandle an execution either by the convict or their anxious relatives. Those lacking the financial wherewithal to induce a corrupt executioner, had an anxious wait to see if the condemned was in an insensible rather than deceased condition when cut down from the gallows. The task of being a lifesaver often fell to penal surgeons with the expertise to revive someone on the boundaries of life and death which inexperienced hangmen had mishandled. Most contemporaries recognised that the capital code was a game of medical chance because it involved the gamble of 'resurrection...not an attitude to death but the last chance to escape it'. ${ }^{3}$ Hence this chapter explores the execution of the condemned from a number of neglected medical perspectives that involved how to determine capital death under the Murder Act, from 1752 to 1832.

To be 'hung by the neck until dead' was a challenging judicial proviso to execute. It often divided opinion in medico-legal circles about which working guidelines would ensure that a convicted murderer was killed

(C) The Author(s) 2016

E.T. Hurren, Dissecting the Criminal Corpse, Palgrave

Historical Studies in the Criminal Corpse and its Afterlife,

DOI 10.1057/978-1-137-58249-2_2 
on the eighteenth and nineteenth-century gallows. It was obvious that the appointed executioner was duty-bound to ensure that the condemned died on the rope. Generally this was either by a broken neck and/or strangulation. Afterwards, the corpse was to be despatched whilst the body was warm, sent to the surgeons to be punished in death. In this way the crowd were alive to the possibility of post-mortem 'harm'. The problem with these legal duties was that compliance was very difficult because officially declaring someone lifeless was not an exact science in early modern England. In histories of the period too often it has been assumed that all criminals, once hanged, were a corpse when in fact archive material reveals that a significant number were found to be living, not deceased, under the hanging-tree. The physical status of everyone executed for murder had therefore to be double-checked on arrival at dissection venues in ways still misunderstood. Hence, more historical attention needs to be paid to the chief medical dilemma that was at the crux of the capital legislation. Continually the medico-legal fraternity faced an ethical quandary that is still challenging in modern biomedicine-for some people 'becoming really dead...takes time'. ${ }^{4}$ Eighteenth-century standards of medical death (no life-signs in the heart, lungs and brain), as opposed to legal death (the act of being hanged) were thus intermingled with wider considerations of judicial power, reconstruction of the state, and a medical knowledge of death continually in transition. Neglect of the puzzle of medical death is consequently a significant historical oversight, but one that is explicable in the standard literature.

In 1751-2, when the capital legislation was being drafted medico-legal mentalities that looked fixed were in fact very mutable. They fluctuated a lot, even before the new stipulations reached the official statute books. In many respects, the specific duties described were a précis of a very fluid set of 'scientific' aspirations, and it is these that have been neglected. Strictly speaking the condemned body was to be punished by 'taking life' (an eyefor-an-eye retribution) and despoiling the body 'to its extremities' (the literal meaning of dissection). But, as we shall see, these routine measures were never a coherent expression of unifying anatomical methods and practices. Of relevance is that when the new capital statute became law 'old anatomy' underwent a paradigm shift by pursuing what became known as 'new anatomy'. ${ }^{5}$ The body was no longer studied wholly as an object of God's creation or indeed exclusively as an educational tool for medical students. The intention was to promote original anatomical research by exploiting the potential for scientific endeavour afforded by the criminal 
corpses of the capital code. Georgian legal officials and medical men thus recognised, as Joanna Innes explains, that eighteenth-century parliamentary legislation was usually drafted in a cursory manner and 'often did not commend itself to eighteenth-century Britons' ${ }^{6}$ It had to be written with 'a sufficient level of generality to cope with diverse local circumstances'. What then looked like a fixed set of punishment rituals involved a great deal of speculation. Over time, the criminal body became a contested medical commodity, synonymous with oscillating ideas about the mutable boundaries of life and death. By the 1780s these encompassed the complex nature of dying, medical death, and physical vitality. Effectively this research emphasis complicated the practical workings of the capital legislation. If the hangman could not execute his duty, then it fell to the penal surgeon to complete the task of execution. This was what really tarnished the medical fraternity in the presence of the post-execution crowd: an outcome often misconstrued in standard histories of the period.

There have then been a lot of basic misconceptions in crime and cultural studies about the practicalities of executing post-mortem 'harm' under the Murder Act.' The legal phrase 'dissection and anatomization' is still used without medical precision. It tends to be misread as a general statement that on safe delivery of a murderer's body the surgeons had the exclusive authority to cut up the corpse in the dissection theatres of Georgian England. This chapter takes issue with this misleading impression. It shows that there was a lot of medico-legal indecision about the 'balf-hanged, 'dead-alive', and 'nearly dead'. As life ebbed from the criminal body medical men debated death's bodily ambiguities, particularly how to monitor metabolism and vitality with such limited medical equipment. Effectively, this meant that 'dissection and anatomization' were redefined as two separate punishment procedures by surgeons working under the capital legislation. The first duty was called 'anatomization' that became associated with a set of checking-mechanisms to determine whether life-signs had deteriorated enough to bring about medical death. The second duty was termed 'dissection' and involved cutting the body 'on the extremities to the extremities' by dismemberment until the murderer was despoiled as a human being. This state of being less than human did not begin until a lifeless state had been established medically, even though the prisoner deserved their punitive treatment according to common law and there would be very little human material to be buried at the end to complete the capital sentence. Surgeons had hence the legal discretion to pragmatically define their working-duties when a body arrived at a dissection venue. 
Most acknowledged that it was very difficult to precisely know whether when a criminal stopped jerking on the executioner's rope those physical signs indicated medical death or not. A condemned body might start to expire, but it also could be shutting-down to protect its vital functions in physical trauma. A liminal state of pain was often disputed in the eighteenth-century medical press too, with surgeons in the capital disagreeing with their provincial counterparts about whether murderers died painfully on the gallows or not. After the condemned departed from the courtroom, the physical showcase that followed as punishment rites unfolded could be rather perturbing for the officials in charge. This was the clandestine side of the Murder Act and it is what this chapter is all about.

The complex ways that medico-legal officials defined medical death in the eighteenth and early nineteenth centuries is the detailed subject of Section l's discussion. This context is necessary to appreciate the medical condition of the condemned body in its criminal setting. Then Section 2 investigates each punishment step in situ, starting with a body on the hangman's rope moving into the realm of physical trauma as life ebbed away. The main focus is the working protocols for establishing medical death in the heart-lungs-brain. Any procedural modifications are identified in terms of their continuities and change over the course of this book's chronological focus to better engage with early modern mentalities of death and dying. Section 3 then re-examines what it meant to come to a medical recognition that executed criminals were in a physical state of 'dying by degrees'. This could occur both hanging from the rope and/or underneath the gallows. Medico-scientific thinking was continuously being tested by working hands-on. New ideas about the potency of human vitality nevertheless complicated how the criminal body was viewed on arrival at dissection venues. It will be shown that some penal surgeons did contravene the Hippocratic Oath with the lancet to hasten death. Others disputed their unsavoury duties in private practice and licensed surgical circles; increasingly these sorts of anatomists monitored the dying processes with caution. Records survive of leading penal surgeons making a detailed record of its metabolic timing. Their influential work could not however prevent the controversial issue of medical death by capital punishment being opened up to public scrutiny in the provincial press. The majority of medico-legal officials henceforth adopted a choreographed set of punishment stages so that they could function ethically and practicably under the Murder Act. Its working framework was: first hanging (legal death), then being anatomized (medical death), and 
finally dissection (post-mortem punishment). ${ }^{8}$ Its widespread adoption (as we shall see throughout this chapter) indicates that it is historically inaccurate to elide 'dissection and anatomization' into a single description of post-mortem punishment. ${ }^{9}$ The last moments of existence were seen as a grey ethical area. ${ }^{10}$ Amongst anatomists the general attitude was that it was the province of 'the doctor... to determine when officiousness became torture'. ${ }^{11}$ The predicament of managing medical death by penal surgeons was to cast a long shadow over the Murder Act from its inception.

\section{'DeATH: THE UNCERTAIN CERTAINTY!'?'2: ACCOMPANYING the Departed into Medical Death}

Near-death experiences were routine occupational hazards for penal surgeons and ones that were well-known to the medico-legal fraternity of mid-Georgian England. Logistical issues remained however largely in the 'private', rather the 'public' sphere to avoid bad publicity. Their rediscovery in the archives has therefore important implications for a wide range of early modern histories of the body and criminal justice. ${ }^{13}$ It is a material fact that in all human beings vital metabolic processes have always been, and remain, capable of shutting down to keep someone experiencing trauma alive. In the past, this meant that the choreography of postexecution rites could be as emotive, engaging, and powerful, as the formal execution spectacle itself. What made routine punishments compelling was that sometimes both the hangman's rope and the lancet were needed for the condemned to become a corpse. That being the case, it is essential to accompany the departed on their physical shut-down into the realms of eighteenth and early nineteenth-century medical death. At issue were changing definitions of insensibility, arising out of a baffling array of early modern physic that did not have the scientific capacity to monitor medical death with precision or medical technology to time accurately the complex physical survival-mechanisms of the condemned. Under the Murder Act medico-legal officials anxious to enhance their professional status by handling the criminal corpse were often confounded by death's dominion.

Today scientists and historians recognise that defining the dying process in the past was a lot easier than establishing medical death. As Leslie Whetstine, an American bioethicist, observes: 'One of the more problematical issues in intensive care is not so much what death " $i s$ " but instead "when" death occurs and the operational criteria used to confirm it' ${ }^{14}$ If modern biomedicine can still be confounded, small wonder that an eighteenth-century 
surgeon might be troubled too. A recent article in the Lancet retraces some of the common physical signs of medical death in the past and their medical competency in context:

- Cessation of heart action, respiration and vigour of the body

- Lividness of the back (refuted as also occurring in illness without death)

- Rigor mortis (may be confused with spasm and catatonia)

- Coldness of the body (regarded as a poor sign since after death the body is thought to rewarm as heat convection from inner organs; the thermometer in 1860 improved the use of this criteria)

- Non-pulsatile, pale-yellow arteries

- No blood flow from transacted veins or arteries (it was refuted that blood flowed from dead patients for hours)

- Grey, black and cloudy corneas

- No muscle movement after electrical stimulation

- Depression or flatness of the loins, buttocks and jaw

- Relaxation and open state of the anus

- Putrefaction-putrid smell, distention of the abdomen, purple or green spots on the body (may not be different from disease without death $)^{15}$

It was then common in the eighteenth-century once the dying process could be observed to keep checking when the patient approached medical death. Unsurprisingly there were was a long list of checks and balances which reflected the fact that surgeons had to take account of a wide range of medical opinions in the shadow of the gallows. To engage with that contemporary scene we need to try to re-imagine the range of medico-scientific options once the condemned was suspended from the hangman's rope.

The surgeon standing to the side of the gallows in the shadows waited to approach the condemned without agitating the crowd. At Tyburn before 1752 and after the Murder Act newspaper reporters noted that the visible presence of the medical men could cause the crowd to riot to obtain the body for burial. ${ }^{16}$ In a noteworthy example in 1818 involving a notorious case at Godalming in Surrey local newspapers reported that there was such ill-feeling against the two murderers, Chennel and Chalcraft, on the gallows that unlike most homicide cases 'there was no danger... that an overwhelming crowd would create any confusion' and 
make off with the bodies. ${ }^{17}$ The same newspaper reporter commented on a contemporaneous case at 'Greenwich where a murderer named Hussey' had been 'rescued by the mob' because local people thought the law had been too harsh. There was a risk of a public order situation getting out of control, and this meant that by the time the surgeons had a chance to get their hands on the body it was often cut down, lying in a cart on the way to the dissection venue. And this observation is significant because the executioner and sheriff's officers would have had very rudimentary methods to establish medical death at the gallows compared even to surgeons. Leaning then over the body there were three very basic confirmatory tests under the hanging tree:

- Signs of "sensibility"-blowing a strong stimulant such as a hellebore or mustard into the nose-inserting a sharp instrument under the nail—scalding with hot water or oil-trumpeting or loud noises

- Holding a mirror, soap bubbles, feather or candle to the nose to detect respiration...

- A container of liquid was placed on the abdomen, or in a decubitus, on the $11^{\text {th }}$ rib; no motion of the liquid indicated death ${ }^{18}$

It is debatable that any of these were carried out with precision given the unpredictable mood of the assembled crowd and the fact that the weather on the day of execution was an added medical complication.

All of these logistical problems are observed in the case of 'Abraham Dealtry' tried and found guilty of highway robbery during 'Lent on 6 April 1745'; his subsequent execution was staged during a very cold and inclement springtime in York. The Morning Advertiser and London Evening Post both reported that: 'Body cut down after 10 minutes and put in a coffin ready for burial; signs of life detected on the way to the graveyard; revived and blooded and returned to York Castle Gaol; thereafter sentenced to Transportation for Life at Yorkshire Summer Assizes, Summer $1745^{\prime} .{ }^{19}$ Another well-known controversial execution is that of William Duell aged sixteen who was hanged for rape and murder 'for the space of twenty-two minutes' on a bitter cold winter's day in the capital on 24 November $1740^{\prime} .{ }^{20}$ Sir Richard Hoare the Sheriff for the City of London noted in his diary that after execution Duell's body was taken by hackney-coach to Surgeon's Hall where on being anatomically checked in order to make 'the necessary preparations for cutting him up' by dissection, vital signs of life were observed..$^{21}$ Duell was bled, revived, returned 
to Newgate, and later reprieved-since he was socially, legally, but not medically dead, his sentence was commuted to 'Transportation for Life' too. Given the seriousness of his crime, and his youthful, robust physical condition, the shorter hanging-time in cold weather was the subject of considerable debate. In a noteworthy aside to the reported case, one legal official helpfully explained that:

It is true the sentence was to hang him by the neck until he were dead and this has not been done; but that it is not done is owing to the inattention only of the magistrates, whose business it is to see that the body be lifeless before it is carried away. ${ }^{22}$

When duty-surgeons could not stand openly at the gallows because of crowd antagonism, this source suggests that a local magistrate with very limited scientific training (even less than the sheriff and hangman) had to declare medical death. This fall-back position harked back to the medieval tradition of watching over the executed body in public, a legal rite known as the exitus. ${ }^{23}$ Official medical death in these circumstances was determined by common agreement by those present that vital signs had ceased. There were then lots of local stories about disputed medical death timings that attracted popular attention and these caused a public outcry by 1752 . The balance of the evidence in winter executions suggests that the three basic confirmatory tests at the gallows (outlined above) were sometimes done in a perfunctory manner, hurried, or ignored altogether. Staging a hanging was about a medico-legal performance of the character of medical death. This meant that in the popular imagination the crowd travelled onwards with the criminal body to satisfy themselves that the picture created by the criminal justice system of the condemned in death was based in a medical reality.

There is then a consensus amongst leading early modern historians that 'the eighteenth century brought a growing medical interest in death' and so popular opinion held that 'the doctor must manage the process of ceasing to be'. ${ }^{24}$ The enigma of medical death on the gallows likewise captivated the general public's imagination. Consequently, 'a quite extensive medical press was operating by 1800 - over thirty titles had come and gone; and if few journals achieved longevity before collapsing, or being renamed, new ones were always plugging the gaps'. ${ }^{25}$ Access to this level of new information and the possibility of reading about the 'dead alive', 'balf hanged' and 'revived', reflected more public awareness about the 
innovative things happening in anatomical circles concerning the mystery of medical death. This explains why dissections were potentially exhilarating events in the locality of a murder. Around 1752 the medical press thus became the conduit of 'that perennial eighteenth-century phenomenon, the participation of the lay public in medical debates' with grisly overtones. ${ }^{26}$ Predictably perhaps by the 1820 s sales of popular journals featuring tales of near-death experiences had attracted an avid readership. Blackwood's Magazine catered to this market by publishing in 1827 the startling story of 'Le Revenant' (The Ghost). The narrator, a condemned criminal, was hanged for murder in London, but cheated medical death. He described how -'With the first view of the scaffold, all my recollection ceases' until, 'having awoke, as if from a sleep, and found myself in a bed'. ${ }^{27}$ On opening his eyes, he thought he had been reprieved but was told that he had been hanged for an hour, cut down, bled, and resuscitated by a 'gentleman' with medical skills: 'My condition is a strange one! I am a living man; and I possess certificates of both my death and burial.' Strictly speaking his legal death happened on the scaffold, his social death was marked, but he did not experience medical death. In so doing, his tale reflected ongoing speculation about whether those executed for murder died on the gallows or inside designated anatomical venues. Incidents started to preoccupy the general public outside of London too.

Thomas Dunn was executed for the murder of Mary Lakin at Leicester city gallows on a bitterly cold day, 25 January 1796 . His body was handed over to a famous local surgeon, Dr Thomas Smith Kirkland of Ashby-dela-Zouche. He got the body because the judge ordered that it be sent back to where the homicide had been committed to be shamed publicly. ${ }^{28}$ In his private diary, Dr Kirkland wrote that because of the greater risk of extreme hypothermia in cold weather, and considerable local feeling against a violent murderer, Thomas Dunn's body was 'exposed to view in the White Horse public house' in the town. This was done over 'three days' under the Murder Act. Dr Kirkland recorded that he worked in full public view of several thousand people. The working procedure was that he first did an anatomical operation that he termed 'anatomization' to check for 'lifelessness', before he proceeded to dissection. The body was washed, shaved, and he made two incisions-one down the chest-one across the torso area-known as the 'crucial incision'-a cross-like cut to observe how the heart and major organs expired..$^{29}$ Many onlookers travelled up from Leicester, seventeen miles away. They did so because Dunn was a soldier in the 5th regiment of the Irish Dragoon guards. He was a physically 
very robust young man, and someone who might be capable of defying the capital sentence on the gallows. Dr Kirkland admitted that he used the opportunity to further his new anatomical research and showcase his skills to his paying customers in the wider community. Later he privately wrote about how the problem of managing medical death 'added to the sense of occasion and its sensational elements'. The balance of the evidence in cases like this one, and others we will be encountering later in this chapter, confirms that there was a medico-legal choreography, it was well-known, and its primary purpose was to reassure those present that the dangerous were dead. ${ }^{30}$ To Dr Kirkland the townsfolk of Ashby-de-la-Zouche were akin to a choir in Greek tragedy, but one not positioned off-stage. By being present their gossip gave public voice to a dreadful anatomical fate. Each medico-legal step dramatized the social, legal and medical death of Thomas Dunn. Later he was dissected, his skeleton boiled down, and displayed in Kirkland's private medical museum.

In many respects the actions of provincial Georgian crowds espoused a version of Aristotle's position that the object of anatomical study was to discover how the soul operated through flesh (be it animal or human). ${ }^{31}$ The moment of medical death seemed to mark the afterlife and the mystery of that life-force had to be stage managed by the criminal justice system (elaborated in Section 2, below). If likewise, as Roy Porter and others claim: 'The eighteenth century brought the development of the medical management of death at the bedside'-and there was a vibrant print culture about the medical limits of mortality and the soul's afterlifethen a medicalization of the capital sentencing process was an intrinsic part of a broader cultural trend that heightened speculation as to precisely what death was' and who specifically had power over it. ${ }^{32}$ An added complication was that 'medicine seemed to be pre-empting the hand of God', but there also continued to be customary 'beliefs about death and the rituals which expressed them' ${ }^{33}$ It was commonplace to try to philosophically debate the nature of life itself. This meant that medical opinions about when the criminal became a corpse became bound up with a better scientific understanding of execution and by extension the limitations of executioners when confronted with near-death situations. Hence when then a leading medical man, Dr A. P. W. Philip, delivered a paper to the Royal Society in London entitled, 'The Nature of Death', there was a great deal of contemporary interest in his review of working definitions and medical opinions that had been in vogue between the Murder Act and publication of his treatise in 1834 . 
Philip in his treatise explained that eighteenth-century medical opinion held that there were 'three distinct classes of bodily function' ${ }^{34}$ These were known as 'the sensorial, the nervous, and the muscular'. The general scientific view was that whilst each 'had no direct dependence on each other'-each could technically function without the other-nonetheless the three systems were inter-connected. It was a physical reality that if one shut down there would be a fatal domino reaction in the other and this would 'more or less immediately destroy the organs of all'. Philip stressed the importance of using precise medical terminology when defining the 'two physiological-stages of death'. The first was popularly known as 'the name of Death' and the second was dubbed 'absolute Death'. ${ }^{35} \mathrm{He}$ asserted that if the sensorial, nervous and muscular systems of the body start to close down, then the heart and lungs would fail. These in turn would have a detrimental impact on the 'sensitive system of the brain and spinal marrow' because blood supply would slow down until it ceased to reach the head. Only however when the sensorial functions had terminated-the organs failed to function-and the sensitive system displayed no physical evidence of brain activity - did 'the name of Death' technically become 'absolute Death.' There were two exceptions-in a 'violent death' at a homicide, or at an 'execution scene'.

By the 1820s contemporary anatomists thought they had 'proved by experiment that in violent death the heart and lungs do not derive their power from the brain and spinal marrow but may be destroyed by impressions made upon them'. ${ }^{36}$ In other words, if a body experienced a major trauma, then that violent assault often speeded up the dying process below the neckline. Meanwhile, anatomists were still exploring at what point medical death actually happened in the brain. Opinion was divided because of the mysterious notion of suspended animation and theological debates about the soul and its afterlife. It was possible, some believed, to become stuck in a liminal metabolic space between life and death. In practical terms, hitting someone over the head could cause the heart and lungs to expire, but not necessarily brain death, since it depended on the level of violent force on the lower part of the body. If however someone stabbed the heart or lungs with a knife, puncturing the major blood vessels, it would cause rapid system failure. In these traumatic circumstances the brain might survive a short-time, but not for long. Brutal violence, in the opinion of Dr Philip and his surgical colleagues, was normally the chief cause of starting to die known as the 'name of Death' in homicide cases. Once the heart and lungs ceased, brainstem death was inevitable but its 
timing could be delayed. To reach the second stage called 'absolute Death' a full physiological shut-down was required..$^{37}$ Only then could a surgeon declare medical death. Philip importantly pointed out that there was an exceptional type of violent death that disturbed surgeons. Medical death was different in 'the struggle of the criminal after the drop falls' on the gallows. ${ }^{38} \mathrm{He}$ claimed that contemporary anatomists and hangmen knew there were different standards of legal versus medical death. That being the case, we need to briefly engage with how anatomical standards had developed, before then considering practicalities at the gallows.

Historians of the body concur that from the Renaissance until the Enlightenment era, the main purpose of the art of anatomy-and it was seen as an art form, not a science, part of Natural Philosophy-was to look inside the human body to 'know thyself. At a time when attending an anatomical lecture was about exploring the discipline's 'grammar, rhetoric... metaphors and analogies', dissection and its 'medical utility' actually 'ranked below the theological purpose' of the anatomical theatre. The primary educational purpose of an anatomical demonstration was to view God's Creation inside the criminal- 'Know thyself and others was the extended message'. ${ }^{39}$ This basic premise was transformed in the so-called 'scientific revolution' when older anatomical methods and their educational value unravelled. It was during this time that 'anatomization' started to strengthen its association with 'living anatomy' and the shutdown of vital forces in the 'dying body': this was Thomas Kirkland's intellectual position in Ashby-de-la-Zouche in 1796 (as we saw earlier). The focus of enquiry was now the puzzle of medical death since it was one of the few original avenues of scientific enquiry left to traditional anatomists once 'anatomy became experimentally matter-of-fact knowledge' after William Harvey discovered the heart was a pump in $1628 .{ }^{40}$ If functioning anatomy was governed by a number of mechanistic theories then exploring how these metabolically closed down during the dying process was a logical way to resuscitate an anatomical tradition of 'anatomization'. This type of reinvention was common down the centuries in the anatomical community and therefore not seen as misleading or intellectually false because the discipline had never been monolithic. It is nevertheless one of the ironies of the criminal justice system that the ability of surgeons to manually revive the condemned, mirrored how anatomists tried to resuscitate their intellectual credibility by deploying their accumulated knowledge about how criminals might be able to defy medical death after 1752. As Andrew Cunningham effectively puts it - 'Each new resuscitated body resulted from a new and distinctive research programme in anatomy', ${ }^{41}$ 
Dissection by contrast became associated with studying the 'pathology of the corpse' after medical death. Confusion has arisen in criminal history about the relationship between anatomy and dissection under the Murder Act because many leading eighteenth-century medical figures practiced both and they never needed to explain their distinctive nature or disciplinary developments since they were well-known to contemporaries. Anatomists, as Roger French points out, by the eighteenth-century had an 'unrivalled technical knowledge of the body'. ${ }^{42}$ They were thus ideally suited to hand over the criminal corpse to in the first instance to examine the mysteries of brain function, cardio-respiratory failure, and to monitor their medical demise. This is why they cut the chest open, examined the major organs, and watched the heart stop beating, checking brain function, and only then proceeding to dissection once all signs of life had ceased. One representative example is worth touching on briefly to set these medico-scientific trends in context. The famous case of Elizabeth Ross is well-known in crime historiography. Yet, it is seldom explored from an anatomical angle and the management of medical death. It affords an opportunity to see in broad terms what the key differences were between the working-practices of 'anatomization' and 'dissection' under the Murder Act. As has already been outlined, for centuries both terms had been synonymous with each other. They were used to ascertain a cause of death. This was no longer their function by the time the capital legislation came into effect. Separate procedures were required to declare medical death and then proceed to post-mortem work. One leading penal surgeon left behind remarkably detailed records of how this worked. His case notes on Elizabeth Ross are hence an archetypal historical prism of post-execution punishment being carefully managed by medico-legal officials under the Murder Act.

Elizabeth Ross was executed on 9 January 1832 at Newgate for strangling her murder victim Caroline Walsh. Surviving notes of her detailed punishment rites illustrate that the 'anatomization' procedure was very different from being 'dissected'. The hanged body was received from the gallows by the Chairman of the Board of Curators at the Royal College of Surgeons, who noted carefully:

A longitudinal incision was made from the upper part of the sternum to the pubis and two oblique later ones - The first over the oblique muscle; and second in the direction of the pectoralis major. The incisions were directed to be made through the integuments only. These incisions were made in the presence of the Sheriffs and Undersheriffs who attended the delivery of the body and were afterwards sewed up. The body was ordered to be delivered to Mr Luke or his assistants at the London hospital at six o'clock in the same evening precisely. ${ }^{43}$ 


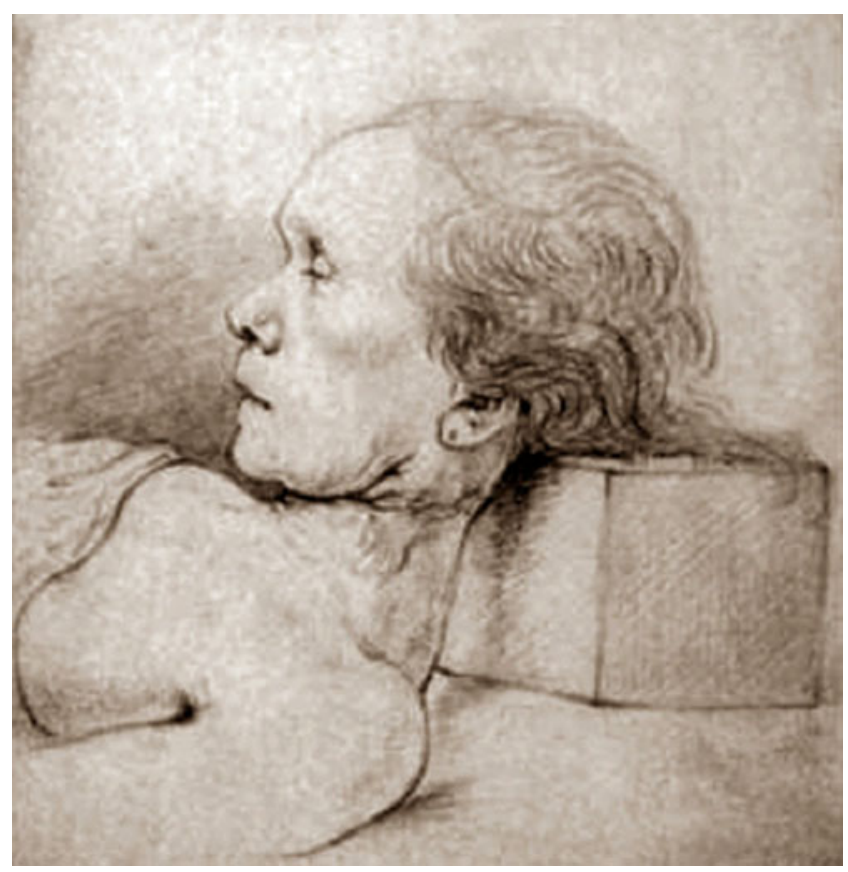

Illustration 2.1 CRoyal College of Surgeons Library, William Clift Collection, Box 67b.13, 'Sketch of Elizabeth Ross' and associated dissection notes on criminal corpses; Creative Commons Attribution-NonCommercial-ShareAlike 4.0 International License (CC BY-NC-SA 4.0)

A private dissection room sketch was later made of Elizabeth Ross (see, Illustration 2.1 above) when she arrived at the London hospital. ${ }^{44}$ It appears to confirm that her torso had not been cut extensively above the breast area. Initially she was opened with two incisions so that the penal surgeon could confirm to the sheriffs and undersheriffs present that she had reached medical death. It is noteworthy that this anatomical check was carried out in a separate location. In medico-legal circles it was commonly called 'anatomization' when it involved a criminal death. The post-execution stipulations of the Murder Act were therefore logistically done in reverse-first 'anatomization' and then 'dissection'. The two initial lancet cuts went down the chest below her breastbone and across the stomach-only cutting into the main muscles and not the deep tissuewhich enabled those present to watch her heartbeat and pulse ceasing 
(rigor mortis having set in after a critical four hours, common to every dying person). She was hence declared medically dead, before being sewn up. Only then was she moved to the dissection venue for the third stage of the death sentence. To shield her human dignity a woollen blanket concealed the initial anatomical marks where she has been stitched up. Record linkage work like this, matching detailed dissection notes to iconic anatomical images of the criminal body, reveals a distinctive medico-legal choreography that requires more careful elucidation in the historiography. Those present would not have followed legal, medical and then postmortem steps if they did not believe it necessary to check that Elizabeth Ross was deceased: a theme we will be returning to in some detail later. Meantime contemporaries knew that natural revival and manual resuscitation did sometimes lead to a full physical recovery and required careful handling after the Murder Act. Medical death in the brain soon became the focus of extensive speculation. To better understand that ongoing context it is necessary to return to what Dr Phillip called 'dying by degrees' in the 'name of Death'.

\section{Dring br Degrees: Deliberating, Disguising, and Disputing Medical Death}

In early modern England, there was a great deal of contemporary conjecture about what today are called anoxic insults to the brain which in the past was termed vitality: this essentially meant that the biomedicine of oxygen starvation was little understood. Any theoretical speculation was based on very limited scientific knowledge about how to define physical trauma in the brain as it went into a state of medical death. It is self-evident this would have mattered a lot at an execution scene. Another practical consideration was that rudimentary techniques to test for vital signs of life in the dying brain remained unsophisticated. These continued to be: shaking the patient, cutting their thumb to get a blood flow, or using a swan's feather on the neck to test for a breathing stimulus. Around 1721, smelling salts became a standard compound in the surgeon-apothecary's medical bag. A few general practitioners by 1744 had access to electric shock instruments when they were first introduced, but many more had to wait until 1800 when they became more widely available in leading medical institutions. By then, in 1803, what brought controversial brain-revivals connected to the capital code to the attention of medical consumers was the famous public demonstration by Giovanni Aldini of electro-resuscitation techniques on a 
criminal corpse executed for murder in London. His case-history was not only the blueprint for Mary Shelley's Frankenstein but it created public disquiet about the medical side of the Murder Act too. ${ }^{45}$ The experiment raised uncomfortable questions about when to declare 'absolute Death'. If the boundary of medical death was 'the uncertain certainty' - to use a contemporary phrase-what, many were asking in print, did that mean for the penal surgeon at the post-execution scene?

Making sure the criminal 'looked dead' was essentially a theatrical reenactment of rough retributive justice in the eighteenth-century. Everyone was in a hurry to get the hanging-stage done, especially in the winter cold or summer heat. The difficult complication of a loss of sensibility in the brain did perturb many of the officials involved and it went on doing so. Dr Philip in his essay on 'The Nature of Death' sets those general debates once more in context:

It is generally supposed that the struggle of the criminal after the drop falls is the measure of his sufferings. The most vigorous suffer most, because in them the sensibility is with most difficulty extinguished; but it is not uniformly in them that this struggle is the greatest. We have reason to believe that it is little, if at all connected with the feelings of the sufferer. ${ }^{46}$

At first glance this seems to be a reasonable assumption given that early modern medical science was improving its working knowledge of cardiorespiratory failure and brain malfunctions. Yet, much of this is also painful conjecture too. Phillip appears to be arguing in 1834 that just because a body jerks on the gallows before going stiff does not mean that the criminal is either sensible of what is happening as s/he dies, or for that matter is in excruciating pain during the whole execution itself, as the penal punishment intended. He could not know at the time but a lack of physical jerking might in fact have indicated a faint trace of brain-stem function (see below): his observations are therefore prescient for someone with limited medical equipment. Instead he tells us what he can claim to know, namely that human beings vary considerably in how they react under extreme stress. Some people have higher pain thresholds than others. The body is capable in certain conditions of terrible fear of closing down to protect what he calls, 'The Laws of Vital Functions'. ${ }^{47}$ Philip states that in his experience 'all such convulsive motions are the same nature'. He calls this a medical condition of "subsultus tendinum' - and notes that it is often observed 'in fever' patients. The person suffering from a high fever is not unlike someone being executed on the gallows. Philip remarks they have 
'little sensibility' about what is happening to them once they start to convulse. Physical jerking is triggered to protect the body. The limbs might shake and then stiffen, but these can in fact be medical indications that the body is shutting down to protect itself in some way that early modern science still has yet to understand. They do not guarantee that the person is experiencing extreme pain or in a state of 'absolute Death'.

Evidence like this, indicates that the physical predicament of being stuck in a dying state in the brain was the ongoing subject of lively debate amongst penal surgeons in the private sectors of eighteenth and early nineteenth-century life. What emerges from local disagreements is just how much medical men deliberated, disguised and disputed medical death, especially in the colder climes of eighteenth-century England. In many respects they were hindered by the same practical dilemma as modern doctors:

Hypothermia can...mimic brain death. At body temperatures below 32 [degrees] C (90[degrees] F), a patient may lose all brainstem reflexes, be tachycardic, and be unable to shiver, depending on the degree of hypothermia. Most healthcare professionals have heard the expression, "a patient is not dead until warm and dead." A brain death diagnosis can't be made until the patient's core body temperature rises to at least 32 [degrees]. ${ }^{48}$

An added problem continues to be that: 'In patients suffering severe facial trauma, pupillary assessments can be difficult or impossible to perform due to severe oedema [accumulation of bodily fluid]'. This was the case for those that died on a rope from strangulation. For centuries doctors looked out for what is often called 'waggling in the eyes' to determine brain malfunction that is terminal. This involved: an inspection of the eyes for fixed dilated pupils, absence of corneal reflexes, cloudiness of the cornea, and loss of eye tension. In capital death however where there was often a delay in getting to the criminal body, penal surgeons had to work with faces swollen by the effects of suffocation and this made it more difficult to examine blood pooling of the eye capillaries. In which case there was the option to do a set of further hands-on procedures that have not changed radically since the early nineteenth-century but can be better monitored with more sophisticated medical equipment today:

An assessment of ocular movements includes oculocephalic and oculovestibular testing (Cranial nerves III, IV, VI). The oculocephalic reflex, also known as the doll's eye reflex, is assessed next...With the eyes held open, the 
patient's head is turned rapidly horizontally and vertically and eye movement is observed. If the oculocephalic reflex is present, the eyes move in the direction opposite to head movement. If the oculocephalic reflex is absent, which is consistent with brain death, the eyes remain midline with head movement. ${ }^{49}$

Of relevance was also the option of doing a cold and hot water test in the ear, a variant of which was once familiar to eighteenth-century penal surgeons too. We will be examining these methods below when looking at contemporary case notes. Meantime, here it is helpful to explain the medical circumstances in general terms first because later we will be looking at what medical officials thought their task was behind closed doors when we examine their recorded timings of bodies shutting-down from the gallows:

The head of the bed is positioned at 30 degrees. Then, 30 to $50 \mathrm{~mL}$ of icecold (33[degrees] C) water is injected slowly (over 30 seconds) into each ear, with a 5-minute wait between injections into each ear. Once the water is injected, both eyes are held open to assess for ocular movement. In patients with an intact brainstem, you'll see a slow movement of the patient's eyes to the side of the ice-water irrigation, followed by a rapid corrective movement of the eyes.

An alternative test for assessing vestibular function is bilateral irrigation with warm water (44[degrees] C). Normally the eyes move away from the side irrigated. Simultaneous bilateral irrigation with cold water normally causes downward deviation of the eyes; bilateral irrigation with warm water normally triggers upward deviation. In brain death, eye movement is absent for at least 1 minute of observation. ${ }^{50}$

As we have seen throughout this chapter the modern biomedicine of brain-stem death is still a very complex area of emergency medicine. ${ }^{51}$ The body in extreme cold, or after a head trauma, or when the circulation of the blood is faulty, can reduce its vital systems to a minimum level to try to keep life functioning. Coma is often diagnosed when the brain is rushed with endorphins to deal with extreme pain thresholds. The comatose person is not capable of moving their limbs, some nerves may twitch, but they certainly look dead to the untrained medical eye. The recent use of therapeutic hypothermia in emergency medicine-letting the brain manage major trauma by reducing the temperature of the body to a minimal level after a sudden cardiac arrest following an accident or injury-is one important indication that our historical knowledge of our biological 
survival mechanisms has been inadequate. ${ }^{52}$ In the long eighteenth-century, coroners, doctors, executioners and sheriffs recognised that brain function was a fascinating medical frontier. And the medical protocols they developed have been enduring because they were sensitive to bodily matters that were mysterious, as well as medically-documented.

This medical backdrop explains why at a special meeting of the governors of the Leicester Infirmary on 17 November 1815 (by way of example) the surgeon responsible for carrying out the criminal dissection of corpses on the premises commented:

Medicine is now extending her Empire over diseases more immediately connected with the mind, as well as those which the body is primarily and principally affected - NOR [sic] is she left without encouraging hopes that she shall at length be permitted to explore that dark region, the Brain, which has hitherto too generally been with-holden [sic] from her view, and presented to less enlightened and less scientific eyes. ${ }^{53}$

Others wrote in the same vein to the London Medical and Physical Journal by 1800 . One representative correspondent claimed:

I have seen a dissector ignorant of the most simple things; ... even while he had the knife in his hand ... Much may be learned in the examination of the dead, without delicate skill and profound knowledge; and physicians, apothecaries, and curious persons, possessed only of a slight knowledge of anatomy, might soon be qualified to perform many useful inspections of the dead. ${ }^{54}$

In other words, there were many types of medical actors present at dissection venues who were skilled, semi-skilled, and medically incompetent working on the same bodies. By 1807 (the date of the quoted letter) the profession was becoming more aware that the brain-stem function differed from the heart-lungs. This was essentially because of what medical science was learning from criminal corpses when checked anatomically for life-signs. For this reason the same correspondent admitted: 'I have myself seen no dissection from which I have not learned considerably; for, to use the remark of [Lawrence] Sterne, an ounce of a man's own sense, is worth a ton of other people's. ${ }^{55}$ Seeing is believing - was his key theme, and this hands-on trend highlights why more primary research is needed to explore - the meaning and timing - of anatomization and dissectionsince each medico-legal step still merits closer historical scrutiny. 
In the provinces and metropolitan centres where surgeons assisted executioners they were starting to appreciate what the brain might be capable of doing to preserve life. There developed a more widespread recognition that 'dying by degrees' happened to a lot of criminals on the gallows, and thus penal surgeons developed a number of other confirmatory tests for loss of vitality in the brain, including by the early nineteenth-century:

- A pressure test on veins to show no refill with blood

- Ammonia was injected to test for inflammation of the subcutaneous tissue-if no inflammation, then no signs of vital life ammonia

- Blunt needle inserted into the heart. If cardiac systole occurred, its motions would be transmitted to flags on the ends of the needle

- Shiny needles placed in the biceps; rusting over time suggested death

- Diaphanous test: loss of scarlet red colour of the finger edges when held to the light

- Cutting through the intercostal space and feeling the heart with the finger tip

- Ligature placed around the finger: failure of distal part to become red or blue

- External pressure to the eyes causes permanent (versus temporary) distortion of the roundness of the pupillage aperture ${ }^{56}$

Contemporary publications like Dr Philip's treatise on 'The Nature of Death' inspired penal surgeons to start documenting their more prolonged encounters with criminals cut down from the gallows. On arrival at a dissection venue it became de regueur for leading penal surgeons behind closed doors to record the dying process at the anatomical stage in minute detail. Some of the best documented examples survive today in the archives of the Royal College of Surgeons in London, Turning to their missing medical perspective, complicates the role of the medical profession in the penal process and its painful subtext over the long duration from 1752 to 1832 .

William Clift worked at Surgeon's Hall on bodies executed across London under the Murder Act. He had a long and distinguished career, assisting the famous anatomist John Hunter and working alongside Sir William Blizard. By the early nineteenth-century Clift's record-keeping was meticulous. It reveals that between 1812 and 1830 there are ten out of thirty-five well-documented cases in which he found that the condemned was still alive after judicial hanging — for he privately wrote- 'the heart was still beating after the body was received' ${ }^{57}$ In other words, not 
less than twenty-six per cent had cheated medical death at the gallows and this in a central London location that claimed medico-legal expertise over the English provincial medical marketplace. Self-evidently this must have been a conservative figure of a potentially much bigger logistical problem before the introduction of the 'new drop'. These discrepancies were often highlighted by popular publications, like the Gentleman's Magazine throughout 1787 for instance, which reported that 'criminals have sometimes been found alive after hanging near an hour' under the 'short drop'.$^{58}$ By March 1815, Clift and Blizzard thus together left detailed dissection notes of 'William Sawyer's final death, hanged for murder at Tyburn'59:

Executed 8 o'clock $15^{\text {th }}$ May 1815 in the morning

Body was received at 9.20 in the morning at Surgeon's Hall

9.40am: Body was opened

10.05am: Watched the heart dying

10.30am: Right auricle still contracting but not the lungs

10.40am: The heart and lungs were placed on a dry towel

$11.00 \mathrm{am}$ : The spontaneous action of the right auricle at about a minute and a half intervals, and then remained at rest ${ }^{60}$

At ten minute intervals observations continued until ' $11.40 \mathrm{am}$ ' when a final procedure was enacted to ensure the dangerous body was deceased:

Heart and Lungs were immersed in heated water to about 100 degrees but no motion whatever was produced by the immersion, nor by any future application of the stimulus [by the anatomist's hand]. ${ }^{61}$

Only after these careful anatomical checks did those assembled proceed to dissection and indeed Blizard was very careful about keeping the body intact: 'After the parts had been examined by Sir William Blizard they were again returned to the Thorax'. It was noted that the criminal had been on the eve of execution so frightened of the dying process, being very troubled that he might not expire quickly, that 'Mr Box, the surgeon in Newgate called in [to the dissection venue] to say he thought the prisoner tried to poison himself'. Box admitted that he felt merciful towards the suicidal man. To calm him down he 'gave him a cordial medicine to enable him to undergo his sentence'. That action speaks volumes about changing medical perspectives of the execution process. Scientific understanding of a slow medical death in the brain and a related drugs overdose reflected how 'absolute Death' was still indeterminate. For this reason Clift and Blizard were thorough, and thus a final entry reads: '29 year old, 5 
foot 10 or 11 , dark hair and remarkably delicate skin, well-grown man' was 'truly dead'.

Another case from a similar notebook is worth examining briefly because of its remarkable detail and the wider clinical lessons that can be drawn from it. ${ }^{62}$ On Monday 24 January 1814 Martin Hogan was executed at Execution Dock in London (the location for the death penalty for serving military men and those found guilty of homicide on the high seas) for the murder of Lieutenant Johnstone. The body was cut down from the gallows and sent to Surgeon's Hall within two hours. This was a fast delivery-service by the blackguards who were paid to transport the criminal corpse from the docks near the shoreline at Wapping, north of the Thames, along the river to where the Old Bailey stands today, across the road from St. Bartholomew's Hospital in the City of London. The dissection notes stated that Sir William Blizard was prompt: 'arrived a few minutes afterward and superintended the dissections.' First however he performed the anatomical checks required by the penal code termed 'anatomization'. This he did by carrying out a number of remarkably detailed and precise confirmatory tests for medical death. To make these engaging for the lay reader the original quotations are cited and in brackets there is a clinical explanation about what he said he was doing, and why, to set medical death protocols in context at the time:

A needle was immediately introduced through the coats of each eye to the Iris, but no visible effect was produced [checking for brain stem function first and then for signs of waggling in the eyes which confirms blood circulation has stopped].

On opening the cavity of the Thorax some of the adhesions were observed between the lungs and pleura but no fluid whatsoever [then checks cardiorespiratory failure]

In the cavity of the pericardium was contained about three drams [it was a winter hanging and he is concerned about extreme hypothermia so he checks the thin double-layered sac which encloses the heart ${ }^{63}$

No motion was perceivable in either ventricle [of the heart], or the auricle to the left side; but in that of the right, very violent contractions took place, beginning at the apex of the auricle and proceeding regularly towards its base [there were vital signs shutting down but not as yet medical death ${ }^{64}$

The notes explained that from 12 noon when the body came into the dissection room 'the contractions became gradually weaker till about half 
past 2 o'clock when they entirely ceased'. And this on a criminal corpse that hung for an hour on the gallows- then was transported across Londonand for the next two hours still was not in a state of 'absolute Death'altogether four hours post-execution. Blizard was sensitive to this medical possibility, and it is noteworthy that by $1814 / 5$ he checked brain function first and then cardio-respiratory failure. Those new procedures reflected how medical understanding of oxygen deprivation and brain vitality were in transition. Thus he decided to carefully double-check the blood flow from the weakening contractions to test their physical function. The notes explained that: 'In the early part of the examination it was necessary to stimulate the auricle; in doing this, a small puncture was made into its cavity by which a considerable quantity of blood issued ... made it necessary to compress the heart from time to time, and make the auricle turgid in order to observe the contractions'. Blizard was inquiring, fascinated, patient, meticulous and methodical because medical death had complex organic processes. He learned from a 'living anatomy' experience in which he also side-stepped human vivisection by performing an act of euthanasia. It is this multi-faceted medical choreography that made the anatomical checking-mechanism of penal punishment termed 'anatomization' distinctive from 'dissection'. For reasons of precision, the lancet was the instrument of medical death and then the implement of post-mortem punishment, in compliance with the sentiment of the Murder Act.

Against this backdrop, disputes and debates emerged about what to do about the medical predicaments of the Murder Act. Surgeons were dutybound by the legislation to keep secret the conundrum of medical death. They were also being encouraged at the time to take a corporate view of their ethical predicament. The College of Surgeons had reconstituted in 1745 , finally distancing itself from the barbers. There was little appetite for stimulating any unwelcome public debate about the capital legislation. Any unsavoury revelations threatened to undermine recent professional gains. The sensible recourse was to focus on the offence of grave-robbing and the perennial problem of low-body supply. These, on balance, were more strategic issues that had the sympathy and support of government. This did not mean that the problem of medical death simply evaporated, quite the reverse. Delving deeper in the archives uncovers important differences between medical actions and attitudes in the capital, compared to those in the provinces. In the metropolis the priority was good public relations, whereas those working in the regions were more prepared to discuss their professional dilemmas in public, often to the consternation of their London 
counterparts. In many respects an up and coming surgeon in the provinces who did not seek an establishment career in the capital had less to lose and everything financially to gain by being honest and building trust with his host community. The general historical neglect of regional studies of provincial penal surgeons who worked under the Murder Act has therefore resulted in the problem of medical death being neglected. In one representative example 'dying by degrees' was deliberated, disguised and disputed in the Midlands, opening up controversies to public scrutiny by the 1830s.

In the Leicestershive Chronicle of 28 July 1832, on the eve of the Anatomy Act, a local surgeon wrote an anonymous letter to the editor in which he detailed how the 'Surgical Profession Hitherto was Injured by the Legislature-Dissection of Murderers'. The extract supports the new findings that form the central argument of this chapter namely that: 'As the murderer's body may be legally dissected, anatomy may still be cultivated, though most imperfectly.' The surgeon went on to explain what he meant by 'imperfectly':

By making dissection of the murderer's body a condition of the sentence, it makes the surgeon the finisher of the law, and thus stamps upon the source of anatomical knowledge ... They give not over to the surgeon the body of the murderer for the promotion of anatomy, but for completion of the penalty which the crime of murder is doomed to pay. The hangman executes a portion of the sentence which claims the forfeit of the murderer's life [postexecution] ... Were the scalpel of the anatomist employed by the halter of the hangman, some such effect [medical death] might be derived from it... What has anatomy to do with murder or the anatomists to do with the murderer? They are not participles criminis [participants in the crime], yet they participate in the punishment. It is the business of anatomy to save life, and the object of anatomy is to teach how to save it; and yet not a murder is committed, or a murderer executed, for which and with whom the surgeon and his science are not severely put upon. ${ }^{65}$

There are two ways to read this source- a traditional one common in the historical literature-versus one that looks in context through anatomical eyes.

On first reading this statement could be interpreted as a straightforward compliant by the surgeon that anatomy and dissection are tarnished by the execution process. Indeed many cultural historians like Jonathan Sawday take the view that: 'As the recipient of the bodies from the execution scaffold, the anatomists was fully implicated in the ambivalent rites of judicial power ...nevertheless working at only one remove [author's emphasis] from the grim business of public execution'. ${ }^{66}$ If however we 
factor in the ambiguities of medical death, then there is also an important contemporary argument being made here that is often misconstrued in modern scholarship. On closer reading the extract could be interpreted as complaining that the surgeon is not one step removed from the penal sentence but actually part and parcel of the execution itself because of the problem of medical death. To check if this reading is salient it is necessary through close textual analysis to examine what is being said from a witting and unwitting perspective.

The Leicestershire surgeon begins with a statement of material fact and an ethical concern: 'By making dissection of the murderer's body a condition of the sentence it makes the surgeon the finisher of the law, and thus stamps upon the source of anatomical knowledge'. In this opening sentence it is noteworthy that anatomy and dissection are distinctive parts of the penal process. A first glance, legally they seem to denote postmortem punishment ('the finisher of the law') but there is also something distinctive about a typical execution process that sullies anatomy ('stamps upon it'). Read from the vantage point of what we have learned from other source material in this chapter about troublesome executions at the scaffold, the unwitting testimony is that anatomy is a separate phase of the penal process and by being so the anatomical sciences are blemished in some way that contemporaries appreciated which modern scholarship has seldom engaged with. The writer then elaborates: 'They give not over to the surgeon the body of the murderer for the promotion of anatomy, but for completion of the penalty which the crime of murder is doomed to pay.' This is a very complex sentence to unpack because it is complicated by the way that anatomy developed as a discipline in the eighteenth-century and briefly looking back to its terms sets the extract properly in context.

At a time when an anatomist got hold of a criminal body he had three ways he could study anatomy-'speculative anatomy' (thinking about and studying the body from a theoretical perspective but being hands-off) 'living-anatomy' (examining the life-force and living structures of the body by means of an autopsy on the major organ systems in the chest cavity)and 'morbid anatomy' (examining dead tissue specimens from dissection preparations before cutting the corpse to its extremities). This was further complicated by an accepted idea in the eighteenth-century that the corpse 'even at the very deepest stages of dissection should be represented as still alive' ${ }^{67}$ An unwitting assumption in the above extract is then that certain types of anatomy were not promoted during the penal process. Seldom was 'speculative anatomy' a priority at an execution. There was the possibility of exploring 'living anatomy' because the body was dying not dead. Yet 
in practical terms the surgeon's priority was to work on the body to get it into a state of 'morbid anatomy' in order to complete the capital sentence. Anatomization was thus primarily about getting the body to become a corpse.

That context helps us to critically analyse the next sentence of the extract which stated that: 'The hangman executes a portion of the sentence which claims the forfeit of the murderer's life'. The executioner does not 'hang the person until dead' - he can only guarantee to do a 'portion of the sentence' - to place the body in a position of legal death which means it is medically dying - and this we know from evidence presented in this chapter is one third of the entire capital sentence at best. Notice also the key verb in this sentence- 'claims' - the executioner cannot guarantee-he can make claim to-but that is not the same as saying he ensures that he can forfeit the murderer's life. Again this is then elaborated: 'Were the scalpel of the anatomist employed by the halter of the hangman, some such effect [medical death] might be derived from it'. In other words, in the surgeon's view, the hangman would need to have the medical man at the gallows rope to guarantee medical death and when not anatomy is 'imperfectly' done because it might involve a mercy-killing. Anatomy should be about saving life, but the anatomist's moral position is the opposite. The logic of that argument is that if he is taking life, then technically the person is not in medical death.

This Midlands surgeon's attitude was not in fact that uncommon. It matched for example what many in the London press had been saying since the 1770s. The Public Advertiser on 5 November 1774 for example reflected on medical opinions triggered by famous revivals in the 1760s. It quoted the 'late Dr Barrowby' an experienced barber surgeon who expressed the view: 'That he was less surprised at the Revival of one executed Person, than that many others did not Revive, as he did not think the common Method of Execution was certain Death' ${ }^{68}$ This sets in context why when 'John Howe, alias John Duff' was hanged for murder in May 1788 after the execution was bungled there was a lot of newspaper interest in the biological effects of hanging. John was described as, 'an unhappy man... between 27 and $30 \ldots$ who made a most miserable appearance, being very dirtily dressed, in an old hat and ragged brown great coat' soiled by dirt and disease, 'with a long beard' ${ }^{69}$ On the gallows 'the knot by some accident slipped round to the back of his neck...the consequence of which was, he continued in a kind of convulsive motion for about three minutes'. On being laid out at Surgeon's Hall the medical men acted with 
precaution, carefully inspecting 'the whole face, the ears, and the neck [which] had a general jet-black appearance, never remembered to have been seen in any subject brought there from the gallows'. Here was precisely the sort of fit young man tainted by poverty that presented a logistical challenge to the executioner and penal surgeons. Only their collective memory could be relied upon when checking for medical death.

Evidence like this points to the need for more detailed medical research to move beyond historical clichés that mislead researchers today into thinking that somehow executions and dissections were seamless punishments; they were not. As one concerned legal correspondent in the letter page of the Public Advertiser of the 29 March 1769, exhorted: 'the business of Surgeon's Hall is not to revive and frustrate but to complete the Execution of the Sentence in Cases of Murder'.$^{70} \mathrm{He}$ said this because the medical stipulations of the Murder Act had little substance until the law was actually applied when the body was cut down and opened up. The legislation's primary purpose was physical retribution, but its wording also reflected deep ambivalence and widespread public anxieties about precisely how to establish medical death and the complicit ethical obligations that followed on. As another letter writer to the Morning Post on 2 September 1770 queried: 'Whether a person condemned by the laws of this country, and carried to the place of execution, and is hanged in the usual manner, if that person comes to life, and is seen at large, is not liable to be taken into custody and hanged again, or has suffered the letter of the law by hanging an hour?" ${ }^{71}$ In even asking and contemplating that someone could revive enough to walk away, there must have been anxiety around at the time that historians have overlooked.

Taken together then, witting and unwitting testimony, points to a contemporary sense that the death sentence had to have a medico-legal choreography - one third at the gallows - two-thirds beyond the hangingtree. The question of medical complicity, the degree of moral culpability, and the inherent conflicting emotions there were for designated surgeons were evidently at the heart of some penal experiences. As with all sources each can be read in several ways and there are issues of representativeness that need to be carefully investigated with further research. Nevertheless close textual reading explores the possibility that such extracts can be read anew to facilitate a reassessment of the actual medico-legal workings of the Murder Act. They start to identify with greater medico-scientific precision the penal actions of everyone who actually handled the criminal body on its punishment journey once it had exited the courtroom. 


\section{CONCLUSION: 'I HAVE BEEN HANGED AND AM ALIVE'72}

To be 'hung by the neck until dead' on the scaffold was never legally guaranteed under the Murder Act. It could not be for the practical reason that death was a medical mystery in early modern England. What happened to the criminal body was that it did not become a corpse until its metabolic processes stopped functioning in the heart-lungs-brain. This biological shut-down then created a cultural sense that there was the deep time of the dead'. In the process of which contemporaries appreciated that 'becoming really dead...takes time'. ${ }^{73}$ Even so, the physical logistics of such a basic medical dilemma at the heart of a capital punishment system ought not to have been neglected by historians of crime. ${ }^{74}$ Retrospective medical diagnosis is an unsatisfactory historical tool. It has been necessary therefore to relocate contemporary medical case histories of the condemned in a dying state to investigate continuities and changes in procedures for establishing medical death. For too long these have been neglected in punishment histories that claim to know the theory but neglect to engage with an empirical picture of contemporary medical problems. This chapter has thus set out the early modern terms of medical reference and the working definitions that defined death, dying and vitality for England. The balance of the evidence suggests that those who witnessed an execution saw not a half, but just one third, of the penal process at the eighteenth and early nineteenth-century gallows. There was social and legal death (being condemned and hanged), medical death (being anatomized) and post-mortem punishment (being dissected). It follows that if a missing two-thirds of the punishment rituals came after the scaffold, then there must have been contemporary reasons for this, and their medical choreography is a crucial and neglected aspect of histories of crime and punishment covering the period 1752 to 1832 .

Detailed dissection cases recorded at Surgeon's Hall reveal that a considerable number of those who were executed died in the dissection venue, not on the gallows. In London the newly constituted College of Surgeons had a policy of only circulating such sensitive findings within their professional circles. They preferred not to discuss its details publicly because they were self-evidently already tarnished by being connected to penal punishment and dissection. The problem of medical death threatened to intensify cultural revulsion at a pivotal time of early professionalization. Alternative arguments in favour of widening dissection to say patients dying in hospital might moreover be undermined if heightened 
cultural sensitivities were exacerbated by any discussion of the long-confusion surrounding medical death; something the Westminster Journal called for in its edition of 20 December $1746 .^{75}$ Against this backdrop it is worth reiterating that of the thirty-six detailed dissections recorded by Williams Blizard and Clift in charge of anatomical procedures on behalf of Surgeon's Hall between 1812 and 1830, there are ten well-documented cases in which the condemned was still alive after judicial hanging. ${ }^{76}$ They claimed a level of expertise supposed to be beyond the capacity of provincial surgeons, which implies that this is a very conservative figure of a potentially much greater logistical problem, especially before the introduction of the 'new drop'. Their caseload profile was typically a robust adult (male and female) of average health aged between twenty-nine and sixty with the majority being in their forties at the time of execution, and hanged in, either January (very cold weather), or May (in hotter years) or September (unseasonal Indian summers). Warm and cold weather patterns, coupled with noteworthy physical characteristics like 'a strong neck', and all having been cut down 'within the hour', were common observations in the case notes. Clift also carefully noted the physical strength of the condemned. Most were rough, big men or women, bullnecked, imposing characters, with a strong will to survive. Many were navies, agricultural labourers, men who were blacksmiths, or did a labour intensive trade-and these robust body types appeared to have a higher pain threshold, or quickly stopped jerking on the rope (probably indicating a physical shut down in the body to protect the brain thereby increasing the chances of survival). Overall, in 27.7 per cent ( 10 of $\mathrm{N}=36$ ) of Clift and Blizard's anatomical cases before dissection it was 'observed the contractions of the heart', 'the observable vital signs', and when handled the heart 'produced a stimulus': all suggestive of cardiac action with the potential to undergo manual resuscitation provided the blood could be oxygenated enough. That many did die on the gallows should not lessen historical interest in those that did not.

These new findings also set in context a much misunderstood report in 1819 of The Committee for Investigating the Criminal Law overseen by central government. ${ }^{77}$ In an appendix to these British Parliamentary Papers a breakdown of hanging offences committed and their respective death-sentences was recorded. ${ }^{78}$ Compiling these and doing so with data from the Sherriff's cravings held at the National Archives makes it feasible to arrive at a conservative estimate of around 5 per cent of convicted cases being sentenced to post-mortem punishment for homicide between 1752 
and 1832 in England and Wales. ${ }^{79}$ If that contemporary figure is accurate, it begs the uncomfortable question what physically happened to the remaining ninety-five per cent who committed lesser capital offences and were just sent to the gallows? The vast majority were hanged but were not sentenced to undergo 'dissection and anatomization'. Some would have expired on the gallows from fright or shock within the hour. But others could have taken much longer to reach medical death. At present, we have cannot know the precise numbers involved; nonetheless this historical gap is significant given that in the case of those that took longer to expire there was no lancet to commit a mercy-killing. In a lot of contemporary accounts friends and relatives from the crowd assisted the hangman by pulling on the body to help break the neck on the gallows or prayed for the long-drop to work efficiently. Seen afresh in the context of a prolonged medical death those actions are not just explicable, but unequivocally merciful. Hence, the early modern crowd waited, watched, and witnessed the condemned body closing down in preparation for dissection in ways often misconstrued. In the next chapter we encounter just what a bad shape the criminal was in as ordinary people crowded round the co-called corpse as it reached its post-mortem destination.

\section{Notes}

1. V. A. C. Gatrell, (1996 edition), The Hanging Tree: Execution and the English People, 1770-1868, (Oxford: Oxford University Press), pp. 45-89.

2. P. Linebaugh, (1975 edition), 'The Tyburn Riot Against the Surgeons' in Douglas Hay, Peter Linebaugh, John G. Rule, E. P. Thompson and Cal Winslow eds., Albion's Fatal Tree: Crime and Society in Eighteenth-Century England (London: Verso), pp. 65-117, cited pp. 85, 102-3.

3. Ibid., pp. 102-3.

4. Thomas Laqueur (2011), 'The Deep Time of the Dead', Social Research, Vol. 78, Fall, III, 799-820, quote at p. 802.

5. A. Cunningham (2010), The Anatomist Anatomis'd: An Experimental Discipline in Enlightenment Europe (Aldershot, Hampshire: Ashgate), preface p. xxi, points to a 'seismic' shift in anatomical practices by the last decade of the eighteenth-century.

6. J. Innes (2009), Inferior Politics: Social Problems and Social Policies in Eighteenth Century Britain, (Oxford: Oxford University Press), p. 105.

7. Refer, J. M. Beattie (1986), Crime and the Courts in England, 1660-1800 (Oxford: Oxford University Press), pp. 520-30; Hugh Amory (1971), 'Henry Fielding and the Criminal Legislation of 1751-2,' Philological 
Quarterly, Vol. 50, 175-92; Richard Connors (2002), 'Parliament and Poverty in Mid-Eighteenth-Century England,' Parliamentary History, Vol. 21, 207-31.

8. Anatomization has tended to be given a modern spin in standard historical accounts, rather than an early modern focus within a working context of the criminal law of the Murder Act.

9. This is often the case in general cultural histories of the body, like, Helen MacDonald (2005), Human Remains: Dissection and its Histories (New Haven: Yale University Press).

10. The term 'euthanasia' is being used here to describe a 'mercy-killing where medical death is an unnatural event in a person's life', see, Ian Dowbiggin (2007), A Concise History of Euthanasia: Death, God and Medicine, (New York: Rowman \& Littlefield).

11. Roy Porter (2003), Flesh in the Age of Reason: How the Enlightenment Transformed the Way We See Our Souls and Bodies (London: W. W. Norton \& Co), p. 223.

12. This contemporary eighteenth-century phrase is often repeated in modern science books on the controversial subject of medical death, see, Dick Teresi (2012), The Undead: Organ Harvesting, the Ice-Water Test, Beating Heart Cadavers - How Medicine is Blurring the line between Life and Death (New York and London: Vintage).

13. See, Michel Foucault, (French edition, 1979) translated to English by Sheridan, A. (1995), Discipline and Punish: The Birth of the Prison (New York: Vintage Books); Colin Jones and Roy Porter eds (1994), Reassessing Foucault: Power, Medicine, and the Body (London: Routledge); Jonathan Sawday (1995), The Body Emblazoned: Dissection and the Human Body in Renaissance Culture (New York and London: Routledge); Roy Porter (2003), Flesh in the Age of Reason: How the Enlightenment Transformed the Way We See Our Souls and Bodies (London: W. W. Norton and Co).

14. Leslie M. Whetstine (2008), 'The History of the Definition(s) of Death: From the Eighteenth-Century to the Twentieth-Century', in David W. Crippen ed., End-of-Life Communication in the ICU, (New York: Springer-Verlag), pp. 65-78, quote at p. 65.

15. David J. Powner, Brice M. Ackerman, and Ake Grenvik (1996), 'Medical Diagnosis of Death: Historical Contributions to Recent Controversies', Lancet, Nov. issue, panel 2, p. 1220.

16. See, Linebaugh, "The Tyburn Riot", pp. 65-117.

17. 'Report and Trial of Chennel and Chalcraft', The Observer, 16 August 1818, pp. 1-14, quotes at p. 10.

18. Powner, Ackerman, and Grenvik, 'Medical Diagnosis of Death', p. 1221.

19. Morning Advertiser, 29 March 1745; London Evening Post, 11 April 1745. I am grateful to Professor Peter King for alerting me to this case, also cited 
in Rhiannon Elizabeth Markless (2012), 'Gender, Crime and Discretion in Yorkshire, 1735-1775' (unpublished, MA Dissertation, Department of the Humanities, Roehampton University), p. 146.

20. Andrew Knapp and William Baldwin eds (1828) The Newgate Calendar, 1824-8 (London: J Robin and Co), 'Case of William Duell, Executed for Murder, Who Came to Life Again While Preparing for Dissection in Surgeon's Hall' e-transcript available on http://www.bl.uk/learning/ images/21cc/crime/transcript 1595.html.

21. Sir Richard Hoare Esq (1815) Journal of the Shrivealty in the Years 1740-1, (Bath: Privately Printed), pp. 37-8.

22. See evidence from contemporary newspapers reproduced in Notes and Queries, 1 March 1854 (No 226), p. 174; 13 March, 1854 (No 230), pp. 453-4; 25 March 1854 (No 231), pp. 281; 25 June 1856 (Number 25), p. 490; 26 July 1868 (No 30), p. 73; Refer, also, London Magazine, 'The Monthly Chronologer: Dewell [Duell]' (1740), pp. 560-1. Magistrates retained the legal duty of checking on medical death at the gallows even after the 'new drop'. Thus the Public Advertiser 20 January 1792 reported that magistrates in Scotland permitted the condemned to 'be applied for by some Surgeons, in order that the usual experiment might be made upon his body for the restoring him to life'. After he was laid out to check his medical death 'a noise was heard' and the magistrates sent for. It turned out to be a dog barking 'who had been locked up in the Hall with the corpse'!

23. See, Jussi Hanska (2001), 'The Hanging of William Cragh: Anatomy of a Miracle', Journal of Medieval History, Vol. 27, 121-38, quote at p. 131.

24. Porter, Flesh in the Age of Reason, p 223.

25. Roy Porter (1992), 'Medical Journalism in Britain to 1800' in W. F. Bynum, Stephen Lock and Roy Porter eds. Medical Journals and Medical Knowledge: Historical Essays (London and New York: Routledge), pp. 6-29. q. at p. 9.

26. Ibid., p. 15.

27. Henry Thomson (1827), "Le Revenant", Blackwood's Magazine, Vol. 27, 409-16, quotes at p. 416.

28. See, Leicestershire Record Office, [hereafter LRO], DE3182/1, The Diary of Thomas Kirkland Surgeon of Ashby and family, c. 1731-1931, entry 25 January 1796; Kenneth Hillier (1984), The Book of Ashby-de-laZouche (Buckingham: Barracuda Books Ltd), p. 123. Kirkland would later be an expert witness as the infamous case of Earl Ferrers.

29. Cunningham, The Anatomist Anatomized, pp. 6-7 explains this standard sequence was derived from work by the leading Bolognese anatomist Marcello Malphigi-'first the belly, then the chest, then the skull'. 
30. Inclusion/exclusion and its practical management are elaborated in Section 2 , below.

31. On Aristotle's anatomical views refer, Andrew Cunningham (1997), The Anatomical Renaissance: The Resurrection of the Anatomical Projects of the Ancients, (Aldershot, Hampshire: Scolar Press), p. 16.

32. Porter, Flesh in the Age of Reason, quotes at p. 222 and p. 216.

33. Ibid., quotes at p. 225 and p. 226.

34. Dr. A. P. W. Philip (1834), 'On the Nature of Death', Philosophical Transactions of the Royal Society of London, Vol. 123, 167-198, quote at p. 168. He was a leading doctor, anatomist, and Fellow of both the Royal Society and Royal Society of Literature. See also, Dr. A. P. W. Philip (1831), 'On the Sources and Nature of Powers on which the Circulation of the Blood depends', Proceedings of the Royal Society of London, Vol, 3, p. 64.

35. Philip, 'On the Nature of Death', p. 170.

36. Ibid., p. 181.

37. Philip, 'On the Nature of Death', p. 170.

38. Ibid., p. 192.

39. Roger French (1999), Dissection and Vivisection in the European Renaissance, (Aldershot, Hampshire: Ashgate), quotes at p. 218, p. 219.

40. Ibid., p. 259 on mechanistic theories, and quote at p. 269.

41. Andrew Cunningham, Anatomical Renaissance, p. 128.

42. See, endnote 39 above.

43. Royal College of Surgeons [hereafter RCS], William Clift Collection, Box 67.b.13, Elizabeth Ross case notes and sketch, 1832, anatomized and dissected.

44. These sketches were generally for private consumption by medical men and drawn by artists in the dissection room directed by the Master of Anatomy at the RCS. They are often reproduced in standard histories without checking their provenance and medical circumstances. Illustration, 2.1 CRoyal College of Surgeons Library, William Clift Collection, Box 67b.13, 'Sketch of Elizabeth Ross' and associated dissection notes on criminal corpses; creative commons license authorised for academic use.

45. Giovanni Aldini was Professor of Physic at Bologna University. His famous experiment is often cited in histories of dissection, like MacDonald, Human Remains, pp. 14-17.

46. Philip, 'On the Nature of Death', p. 170.

47. Ibid., pp. 170-2.

48. Teresa E. Hills (2010), 'Determining Brain Death: A Review of EvidenceBased Guidelines' Nursing Volume 40, Vol. 12, Dec. Issue, 34-40, quote at p. 37.

49. Ibid. 
50. Hills 'Determining Brain Death', p. 37.

51. See for example, D. J. Power (1987), 'The Diagnosis of Brain Death in Adult Patients', Journal of Intensive Care Medicine, Vol. 2, 519-25; R. D. Truog \& J. C. Fackler (1992), 'Rethinking Brain Death', Critical Care Medicine, Vol. 20, 1705-13; J. P. Lizza (1993), 'Persons and Death: What's Metaphysically Wrong with our Statutory Definition of Death?', Journal of Medical Philosophy, Vol. 18, 351-74.

52. See, http://www.sca-aware.org/sudden-cardiac-arrest-treatment: 'When a patient undergoes therapeutic hypothermia, it is somewhat startling to feel how cold s/he can be to the touch. This is normal and only temporary. The patient's temperature will be reduced to about $91^{\circ} \mathrm{F}\left(33^{\circ} \mathrm{C}\right)$, approximately $7^{\circ} \mathrm{F}\left(4^{\circ} \mathrm{C}\right)$ lower than normal. The patient will be on a respirator, heavily sedated and unable to move. The therapy typically will last for a maximum of 36 hours: 12 to 24 hours of cooling and up to 12 hours to rewarm slowly back to a normal body temperature of $98.6^{\circ}\left(37^{\circ} \mathrm{C}\right)$. During the cooling process, the patient will require frequent blood samples to make sure s/he is tolerating the cooling procedure well. Sometimes, additional medications can be given to help control blood pressure and heart rate... you will not know anything about his/her level of consciousness until the therapy is completed'.

53. LRO/13064/13, Leicester Infirmary Minute Books, 23 June 1814-30 June 1819, entry dated 17 November 1815.

54. Letter by an English anatomist and dissector who moved to Maine in America, Editor (1807), The London Medical and Physical Journal, Vol. 108, XVII, 155-7, q. at p. 155.

55. Ibid, p. 156.

56. Powner Ackerman, and Grenvik (1996), 'Medical Diagnosis of Death', Lancet, Nov., panel 3, p. 1221.

57. The diary of William Clift was first examined by Jesse Dobson, Recorder of the Royal College of Surgeons in the 1950s and her preliminary archive findings were published in, 'Cardiac Action After "Death" by Hanging', Lancet, 29 Dec. 1951, 1222-4, quote at p. 1223. I am grateful to Wendy Moore for emailing me about this overlooked secondary source in response to a short article this author published in the Lancet in July 2013.

58. Gentleman's Magazine (1787), Volume 57, p. 33, letters to the editor, and Gentleman's Magazine (1787), Volume 62, p. 673, on 'the escape of criminals from death, after hanging'.

59. Author's emphasis since the precise clinical phrasing is noteworthy.

60. RCS, William Clift Collection, MS0007/1/6/1/3, 1807-32, pp. 6-8.

61. Ibid.

62. RCS, William Clift Collection, MS0007/1/6/1/1, 1800-14, 24 January 1814 , pp. 1-2. 
63. Ibid; The fluid is contained within the layers and lubricates the constantly rubbing surfaces around the heart's double-layer. The anatomist can also pass a finger posterior to the aorta and pulmonary trunk (arterial end of heart) and anterior to the left atrium and superior vena cava (venous end of heart). This passage is termed the transverse sinus of the pericardium. The pericardium is supplied by several arteries that are in the area (like the internal thoracic), and by the phrenic nerves, which contain vasomotor and sensory fibres. Pericardial pain is felt diffusely behind the sternum but may radiate and was seen as a sign of vitality.

64. RCS, William Clift Collection, MS0007/1/6/1/1, 'Records of the Murderers delivered to the College for Dissection' written inside the front cover of the book. These records have been used in general histories like that of MacDonald, Human Remains, pp. 13-27. Their importance regarding the timing of medical death and the precise meaning of the practicalities of the Murder Act has been neglected.

65. Letters to the Editor (1832), 'The Surgical Profession Hitherto Injured by the Legislature-Dissection of Murderers', Leicestershire Chronicle, Saturday 28 July, Issue 1140, medical correspondent styled 'PHILANTHROP', pp. $1-5$, quotes at p. 3 and 5 .

66. Sawday, Anatomy Emblazoned, p. 54.

67. Ibid., p. 112.

68. Public Advertiser, 5 November, 1774 (A), column 3.

69. Morning Chronicle, 5 May 1778, column 2.

70. Public Advertiser, 29 March 1769, correspondent styled 'Gracchus' complaining about Jack Ketch; see also SJC, 30 March 1769.

71. 'To the Editor of the Morning Post', Morning Post, 2 September 1770, column 2.

72. Thomson, "Le Revenant", p. 409.

73. Laqueur, 'Deep Time of the Dead', p. 802.

74. Ibid., p. 802 .

75. Westminster Journal, 20 December 1746 (a), column three discussed this at length.

76. See, RSC, William Clift Collection, endnote 57 above.

77. On the workings of the Committee see, Jeremy Horder (2012), Homicide and the Politics of Law Reform, (Oxford: Oxford University Press), pp. 7-11.

78. Refer, BPP, Hansard, House of Commons Sitting (1819), HC debate, 6 July 1819, Vol. 40, cc 1518-36, Sir James Mackintosh said that the murder rate was 67 murders and 57 executed 1755-1784, 54 murders and 44 executed 1874-1814, with 9 murders per annum in London.

79. These estimated figures have been compiled from BPP (1819), The Committee for Investigating the Criminal Law and TNA Sheriff's Cravings 
(see bibliography). I am grateful to Professor Peter King and Dr Richard Ward for assisting me by calculating that a total of ' 735 offenders were executed in England, Wales and Scotland in the ten years between 1776 and 1785 for the capital offences covered by the Murder Act 1752'. The project team are very grateful to Professor Simon Devereaux for providing data for the London court circuit.

This chapter is distributed under the terms of the Creative Commons Attribution 4.0 International License (http://creativecommons.org/licenses/by/4.0/), which permits use, duplication, adaptation, distribution and reproduction in any medium or format, as long as you give appropriate credit to the original author(s) and the source, provide a link to the Creative Commons license and indicate if changes were made.

The images or other third party material in this book are included in the work's Creative Commons license, unless indicated otherwise in the credit line; if such material is not included in the work's Creative Commons license and the respective action is not permitted by statutory regulation, users will need to obtain permission from the license holder to duplicate, adapt or reproduce the material. 